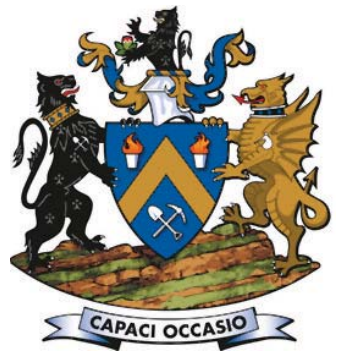

\title{
The new SANS 10320:2016 versus the 2014 Australian guidelines for the estimation and classification of coal resources-what are the implications for southern African coal resource estimators?
}

\author{
by J. Hancox* and H. Pinheiro ${ }^{\dagger}$
}

\section{Synopsis}

The past three decades have witnessed the publishing of reporting codes for all the main stock exchanges, as well as the evolution of a uniform international standard covering the definition, estimation, and public reporting of Mineral Resources. Many of these reporting codes have commodity-specific reporting sections for coal, but only two countries (Australia and South Africa) have specific guidelines for reporting on coal resources. Both of these companion documents (SANS 10320:2016 and the Australian Guidelines for the Estimation and Classification of Coal Resources, 2014) have recently been updated. Unlike their parent codes, which have become increasingly similar, these new guidelines have diverged and are different in a number of significant ways, which in turn will have an impact on coal resource estimators working in the coalfields of south-central Africa, particularly in countries where no commodityspecific guidelines for coal exist.

Keywords

Reporting codes, coal resources, estimation, classification.

\section{Introduction}

Due to various reporting irregularities and the need to protect the investing public, the past three decades have witnessed the publication of reporting codes for all the world's main stock exchanges, as well as the release of an international reporting template for the public reporting of Exploration Results, Mineral Resources, and Mineral Reserves by the Combined Reserves International Reporting Standards Committee (CRIRSCO). Many of the codes now have commodity-specific reporting sections for coal. However, due to the fact that the governing codes have developed to such an extent, some have questioned the need for coal-specific standards. We would argue that coal resource estimation does require commodity-specific guidelines, as the processes of coal formation include aspects that are unique and which are fundamentally different from those that apply to most other mineral deposits. In addition, certain coal qualities may be of special interest for specific uses and technological applications, and may require very specific analytical work.

of the codes that have commodity-specific sections for coal, two are prescriptive (the USA and Canada) and two are descriptive (South Africa and Australia) and are considered as guidelines. Though termed 'guidelines', most institutions involved in the business of coal resource estimation, evaluation, and ultimately with the goal of raising funding, consider these guidelines as prescriptive, and as a set of standards that must be addressed for a Coal Resource to be considered as being reported in accordance with the required code.

While most of the internationally recognized reporting codes have become very similar, including the South African Code for Reporting Mineral Resources and Mineral Reserves (the SAMREC Code, 2007 as amended 2009; 2016) and that of the Joint Ore Reserves Committee (JORC, 2012), their coalspecific guidelines have recently diverged and differ in a number of significant ways.

\section{Estimation of Coal Resources in South Africa}

Coal occurs in South Africa in 19 separate coalfields (Figure 1), each of which has unique characteristics relating to coal formation, and the Competent Person should take due consideration of these characteristics when estimating, classifying, and reporting Coal Resources in South Africa.

Currently, Coal Resources in South Africa must be estimated in accordance with the SAMREC Code (2009), with additional guidelines deemed necessary to standardize the reporting of Coal Resources for securities exchange requirements, being supplied by the South African guide to the systematic evaluation of Coal Resources and Coal

* CCIC Coal (Pty) Ltd, South Africa.

+ Ariy Consulting and Advisory, South Africa.

(C) The Southern African Institute of Mining and Metallurgy, 2017. ISSN 2225-6253. This paper was first presented at the SAMREC/SAMVAL Companion Volume Conference 'An Industry Standard for Mining Professionals in South Africa', 17-18 May 2016, Emperors Palace, Johannesburg 


\section{The new SANS 10320:2016 versus the 2014 Australian guidelines}

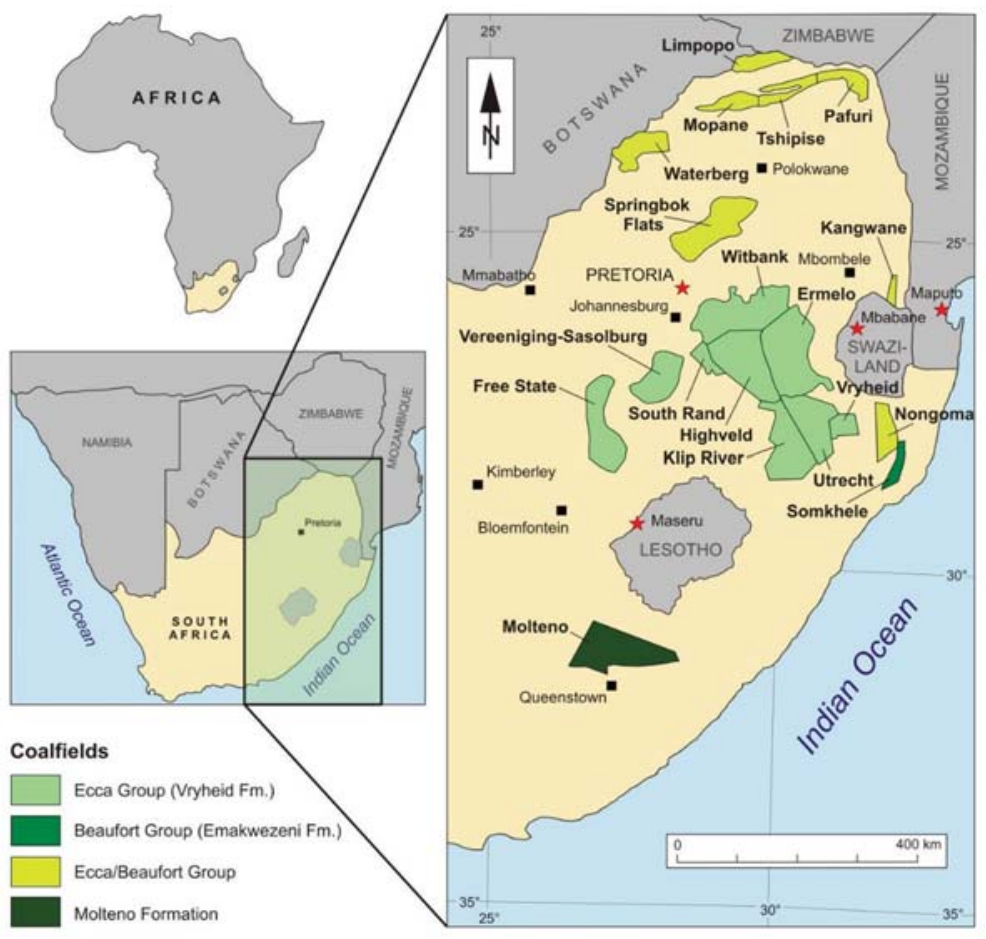

Figure 1-Coalfields of South Africa (Hancox and Götz, 2014)

Reserves (SANS 10320:2004). The standard was originally prepared in conjunction with the SAMREC Code by the SAMREC Coal Commodity Specific Sub-committee. Although not yet published, this guideline has recently been updated as SANS 10320:2016 and has passed the Committee draft stage. Both authors of this paper were involved with this process and were provided with a final draft of the document for use in writing this paper. Once ratified, the new standard will supersede the first edition, and will serve to provide further alignment, clarification, and best practices in terms of the reporting of Coal Deposits, Coal Resources, and Coal Reserves. Dingemans (2015) and van Deventer (2015) have both provided overviews of what the main changes in the new guidelines will be, and these are documented and discussed below.

One of the most significant aspects of the new SANS 10320:2016 standard is that it applies to all Coal Exploration Results, Inventory Coal, Coal Resources, and Coal Reserves within South Africa, irrespective of the jurisdiction within which the reporting is undertaken. This means that the application of other codes and guidelines to South African coal deposits will no longer be allowed, which will prevent the previous poor practice of using the larger drill-hole spacing that other codes allow in delineating South African deposits.

SANS 10320:2016 will provide the methodologies and definitions of the relevant terms that should be considered when preparing Public Reports on Coal Exploration Results, Coal Resources, and Coal Reserves. In terms of the new standard a Coal Resource is defined as 'coal of economic interest in or on the Earth's crust in such form, quality and quantity that there are reasonable prospects for eventual economic extraction'. Tonnage and coal quality must be reported for all entries in a Public Report, per classification category, in order of increasing confidence in respect of geoscientific evidence, into Inferred, Indicated, and Measured categories. The moisture content for all tonnages and coal qualities must be reported.

The determination of reasonable and realistic prospects for eventual economic extraction is fundamental to the definition of a Coal Resource. Under the new standard, in order to classify a Coal Resource, the Competent Person (CP) shall identify that part of a coal deposit for which there are reasonable and realistic prospects for eventual economic extraction, and that will be economically viable to mine and produce a raw or beneficiated saleable coal product. Consideration must also now, for the first time, be given to Conversion Factors, which are considerations used in a geological study to convert Coal Exploration Results to Coal Resources. These include, but are not restricted to, mining, processing, metallurgical, infrastructure, economic, marketing, legal, environmental, social, and governmental factors. Although these factors are similar to the Modifying Factors used to convert Coal Resources to Coal Reserves, they may be more conceptual in nature.

Under the new standard a Coal Resource risk assessment must be undertaken, and any risks that may affect the potential economic viability of the Coal Resource must be clearly stated. If any key variable or combination of variables of the coal deposit under consideration does not meet a level for which there are reasonable and realistic prospects for eventual economic extraction, then Coal Resources cannot be declared, and must be reported only as Inventory Coal.

While SANS 10320:2004 allowed for a Gross Tonnes in situ (GTIS) resource to be publicly stated, the new standard will allow such figures for internal calculation purposes only, and not for Public Reporting. Under SANS 10320:2016, for the Public Reporting of Coal Resources, all tonnages and coal 


\section{The new SANS 10320:2016 versus the 2014 Australian guidelines}

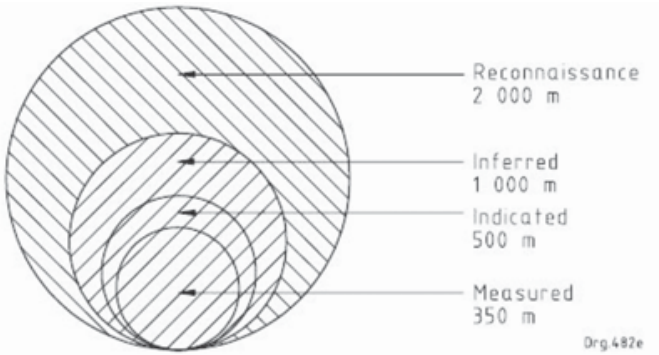

Multiple seam deposit type coal resources ( $<50 \%$ ash)

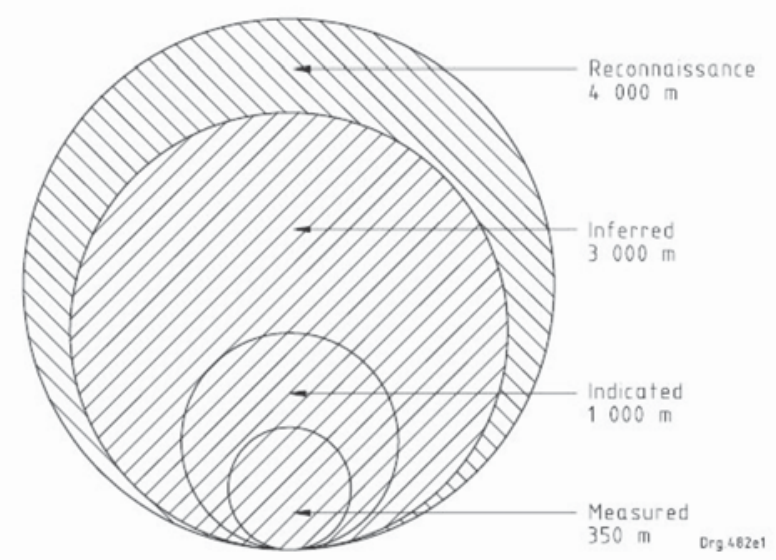

Thick interbedded seam deposit type coal resources (<65\% ash)

Figure 2-Schematic illustration of the minimum borehole spacing for each Coal Resource classification category for the various South African coal deposit types (the minimum distance between boreholes shown in metres). Source: SANS 10320:2004

qualities must be reported on a Mineable Tonnes in situ (MTIS) basis, with the associated yield, coal quality, and moisture content clearly stated. According to Dingemans (2015) the lowest level of Resource that may be publically reported under the new standard would be an Inferred, MTIS Coal Resource. A MTIS Resource is the tonnage and coal quality, at a specified moisture content, contained in the coal seam, or section of the coal seam, which is proposed to be mined, at the theoretical mining height, adjusted by the geological loss factors and derating for previous mining activities, but excluding contaminant material, with respect to a specific mining method, and after the relevant minimum and maximum mineable thickness cut-offs and relevant coal quality cut-off parameters have been applied.

SANS 10320:2016 will still recognize two different types of South African coal deposits (multiple seam and thick interbedded deposit types) and will still allow for resource category confidence to be assessed based on the density (per 100 hectares) or spacing of cored boreholes with quality data. A difference to the previous SANS 10320:2004 guidelines is that the new guideline specifically mentions that different coal deposit types within the same coalfield must be reported separately. In addition, the new guidelines will allow for a maximum $500 \mathrm{~m}$ borehole spacing for the Measured Resource category of thick interbedded coal deposit, as opposed to the $350 \mathrm{~m}$ required in SANS 10320:2004 (Figure 2).

Typically in South Africa, the Free State, VereenigingSasolburg, South Rand, Witbank, Highveld, Ermelo, Klip River, Utrecht, Vryheid, Springbok Flats, lower Waterberg, Somkhele, and Molteno coalfields are multiple seam deposit types, whereas the upper Waterberg (Grootegeluk Formation), Springbok Flats, Limpopo, Soutpansberg (Mopane, Tshipise, and Pafuri) are thick interbedded seam deposit types. The Nongoma and Kangwane coalfields may contain both coal deposit types (Figure 1). SANS 10320:2016 will supply a list of which coalfields contain which types of coal deposits.

\section{Estimation of coal resources in Australia}

The productive coalfields of Australia occur mainly on and around the east coast (Figure 3), predominantly in Queensland and New South Wales, where the coal-bearing sequences show extreme lateral continuity and continuous geometry (Allen and Fielding, 2007).
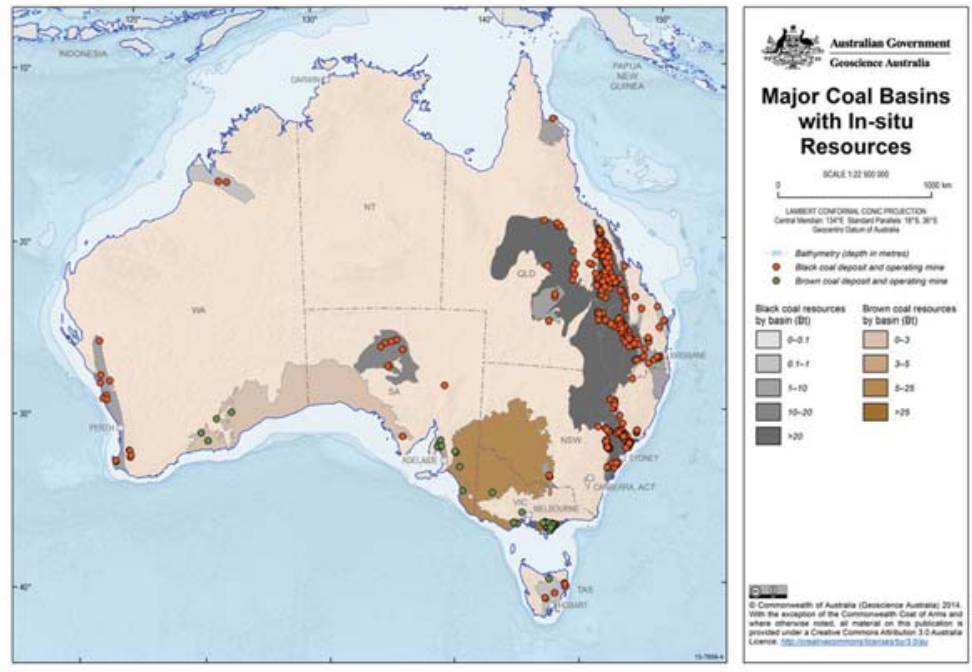

Figure 3-The major coal basins of Australia, showing the position of the hard (black) and soft (brown) coal resources. Source: http://www.minerals.org.au/resources/coal/australias_major_coal_regions 


\section{The new SANS 10320:2016 versus the 2014 Australian guidelines}

Prior to September 1999 the estimation and reporting of Coal Resources in Australia was prescribed by the Australian Code for Reporting Identified Coal Resources and Reserves (February 1986). The first direct references to coal are found in clauses 38 to 40 of the 1999 JORC Code. Until October 2014, the JORC (2012) Code required that Coal Resources be reported on the same basis as any other mineral commodity, with cognisance taken of the guidelines contained in the Australian Guidelines for Estimating and Reporting of Inventory Coal, Coal Resources, and Coal Reserves (2003). These guidelines (2003) stated that a Measured Coal Resource may be estimated using data obtained from Points of Observation usually less than $500 \mathrm{~m}$ apart, an Indicated Coal Resource from Points of Observation less than $1000 \mathrm{~m}$ apart, and an Inferred Coal Resource from Points of Observation less than $4000 \mathrm{~m}$ apart. These recommended spacings were based on historically proven continuity of coal seams in the Hunter Valley and the Bowen Basin. Unlike in the SANS 10320:2004 document, only one set of spacings was used no matter what the type of coal deposit.

Subsequent geostatistical work by Bertoli et al., (2013) showed that the use of a 'one size fits all' classification scheme (even in the well-documented Bowen Basin) may result in inappropriate resource classification (Table I), and as such the use of fixed drill-hole spacing for resource classification was not good practice.

In October 2014 the new Australian Guidelines for the Estimation and Classification of Coal Resources (Australian Guideline 2014) were ratified. This document represents a significant update and marks a major change in the role of the $\mathrm{CP}$ in coal resource estimations in Australia. Probably the most important aspect of this revision is the fact that the concept of defining Resource categories in terms of distance around Points of Observation (which was introduced in 1971 in the first edition of the Code for Calculating and Reporting Coal Reserves by the Geological Survey of New South Wales) has been removed. Instead, the $\mathrm{CP}$ must now assess the

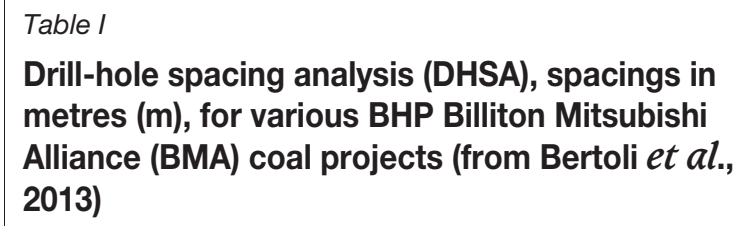

\begin{tabular}{l|c|c|c}
\hline Operation & Measured & Indicated & Inferred \\
\hline Blackwater & 550 & 1050 & 2100 \\
\hline Caval Ridge & 800 & 1400 & 2800 \\
\hline Caval Ridge & 500 & 1000 & 2450 \\
\hline Crinum M Block & 1100 & 1900 & 3600 \\
\hline Daunia & 650 & 1250 & 2800 \\
\hline Goonyella Riverside & 650 & 1250 & 3150 \\
\hline Gregory Crinum & 1100 & 1900 & 3600 \\
\hline Lorus North & 350 & 700 & 1850 \\
\hline Norwich Park & 750 & 1450 & 3550 \\
\hline Peak Downs & 700 & 1300 & 2600 \\
\hline Peak Downs & 850 & 1700 & 4200 \\
\hline Poitrel & 400 & 750 & 1800 \\
\hline Saraji & 750 & 1400 & 2500 \\
\hline South Walker Creek & 250 & 500 & 1000 \\
\hline Coal Guidelines (2003) & 500 & 1000 & 4000 \\
\hline
\end{tabular}

confidence in the estimate of all significant variables, and the most applicable methods and criteria to demonstrate such confidence should be used to support the classification assigned. Such criteria and methods include statistical and geostatistical analyses, as well as the definition of geological domains, and geological modelling. The estimator must also identify any critical parameters that might affect the eventual economic extraction test, or those that may result in contractual penalties. The use of geostatistical methodology, whereby the classification of the resource is driven by the actual in situ variability (or conversely spatial continuity) of the resource, is strongly recommended.

The Australian Guidelines (2014) include a Glossary of terms, which is surprisingly short, and does not include important terms such as 'ply', 'seam', and 'zone'. Yet the concept of ply in particular is vital to the exercise of Australian resource assessment. While the words 'should', 'can', 'may', 'may not', and so on are typical and rather common throughout the guidelines, occasionally 'must' enters the fray. For example, 'seam thickness and location must be unambiguous', in which case it is prescriptive.

For the first time the new Australian Guidelines (2014) recommend that the geotechnical conditions of the overburden, interburden, roof and floor strata, the seam gas content and composition, the propensity of the coal for spontaneous heating, the potential of relevant materials for frictional ignition, and any other parameters pertinent to the consideration of reasonable prospects for eventual economic extraction, should be assessed.

Furthermore these guidelines suggest that a CP must assess all relevant aspects of (and risks to) mining, processing, metallurgical, infrastructure, economic, marketing, legal, environmental, social, governmental, and regulatory factors. It notes that while the assessment can in part be qualitative in nature, there generally needs to be at least a basic quantitative evaluation that considers financial indicators and consideration should be given to whether the tonnage and coal quality are sufficient to ensure satisfactory returns over a reasonable life of mine. These guidelines do not, however, prescribe: a specific approach to arriving at the key assumptions; the level of detail required; the economic indicators that need to be satisfied; the level of satisfaction that needs to be achieved for the coal to be said to have reasonable prospects, and hence be classified as a Coal Resource.

\section{Comparison of the South African and Australian guidelines for coal reporting}

There are a number of instances where the two parent codes (JORC and SAMREC) and coal guidelines are now similar, yet different from their previous versions. The most significant of these are that:

> The controlling Code now requires that Table 1 is completed in both instances

- All reporting must be on an 'if not - why not' basis

> The basis for quality and tonnage reporting must now be in-situ moisture, with the Preston and Sanders (1993) formulae applied for density in tonnage calculations 


\section{The new SANS 10320:2016 versus the 2014 Australian guidelines}

- More importance must be placed on the conversion factors in the stating of a Coal Resource

> A risk assessment is now required.

The Australian Guidelines (2014) require the $\mathrm{CP}$ to assess the likely mining scenario (open cut/cast or underground). For a potential open cut mining scenario, emphasis must be placed on strip ratio, minimum mineable seam thickness, maximum non-separable parting thickness, pit wall stability, and depth of weathering. In an underground mining scenario, aspects such as depth, faulting, igneous intrusions, working section thickness, seam dip, physical properties of roof and floor lithologies, hydrogeology, stress regime, gas content, lithological composition, and permeability should be considered. SANS 10320:2016 will also place more emphasis on geotechnical work, specifically as to how such parameters may influence the potential for eventual economic extraction.

Both documents also place more emphasis on the role of the $\mathrm{CP}$, often extending outside of such person's normal sphere of expertise, with the Australian Guidelines (2014) going as far as noting that these matters are normally considered in concert with engineers and other specialists and that it may be necessary to seek expert comment on these factors. The impact of the latter on the cost of exploration cannot be underestimated, and will be significant, especially for junior miners seeking to operate and deliver against such guidelines. Neither guideline requires the lodging of the CP Report with the controlling exchange, an area which should be addressed.

There are, however, also several differences between the forthcoming SANS 10320:2016 revision and the Australian Guidelines (2014), the main ones being:

- SANS 10320:2016 will still allow the use of maximum distances between Points of Observation for defining resource categories per coal deposit type in South Africa, whereas the concept of defining resource categories on distance around Points of Observation has been removed from the Australian Guidelines (2014), which prefers that the resource classification be founded on the assessment of the confidence in the estimate of all significant variables, based on a series of methods and criteria, such as geostatistical analysis

- SANS 10320:2016 will still prescribe core recovery in excess of $95 \%$ by length within the coal seam intersection of a drill-hole, whereas the Australian Guidelines (2014) state that sample recovery must be considered representative, and that potential loss of material from within a sample may be critical, irrespective of the relative percentage lost; and that downhole geophysical data should be used to confirm the location and nature of any core loss in the coal seam. The use of downhole geophysical data is not prescribed in the new SANS 10320:2016 standard

> The Australian Guidelines (2014) also note that the analysed sample should be representative of the in-situ material within the interval of interest, and as such hints that it is in fact the percentage of material that makes it to the laboratory that is important. SANS 10320:2016 does not state that the received sample at the laboratory must represent $95 \%$ of the recovered material

> SANS 10320:2016 refers to both Coal Resources and Coal Reserves, whereas the Australian Guidelines (2014) is now only applicable to Coal Resources

> In SANS 10320:2016 the only level of tonnage reporting is MTIS; the Australian Guidelines (2014) makes no distinction between GTIS, TTIS, and MTIS and do not mention that geological losses need to be specified

> SANS 10320:2016 specifically mentions that different coal deposit types within the same coalfield (e.g. for the Waterberg Coalfield) must be reported separately, whereas this is not required by the Australian Guidelines (2014), other than as stipulated in section 5.2.2 of the guidelines

> SANS 10320:2016 must be applied to all Coal Exploration Results, Inventory Coal, Coal Resources, and Coal Reserves within South Africa, irrespective of the jurisdiction within which the reporting is undertaken; whereas the Australian Guidelines (2014) are intended for use in Australian coalfields

> The revised SANS 10320:2016 guidelines for Coal Resource estimation do not require the reporting of tonnages beyond the in situ stage. Where the Coal Resource is deemed suitable to be exploited for a washed coal product, the associated theoretical yield and washed target product shall, however, be stated. In the case of the Australian Guidelines (2014) the application of certain quality and potential utilization factors is required, thereby allowing for reporting of a coal quality that is closer to a saleable product

> For the Australian Guidelines (2014) a CP must at least undertake a basic quantitative evaluation of financial indicators, whereas this is not a requirement of the SANS 10320:2016 guidelines.

Despite the Australian Guidelines (2014) stating that it is intended for use in Australian coalfields, it also follows with the wording 'but may also provide guidance internationally', thus leaving the door open for its use elsewhere, such as is the case in the coalfields of Mozambique.

\section{Estimation of coal resources in Mozambique: a southern African example of the application of the two different coal guidelines}

The coalfields of the Tete Province of Mozambique occupy an area stretching over $350 \mathrm{~km}$, from Lake Cahora Bassa in the west to the Malawi border in the east (Figure 4). From west to east these are variously termed the Chicôa-Mecúcoè (including the Mucanha-Vuzi sector), Sanângoè-Mefídézi, Moatize (or Moatize-Benga), Muarazi, and Minjova subbasins, with northwest and southeast extensions Ncondezi (N'condezi) and Mutarara (Vasconcelos, 2012).

In the past decade a lot of exploration focus has been placed on the coalfields of Mozambique. However, at present Mozambique does not have its own reporting code or commodity-specific coal reporting guidelines. The JORC Code has mostly been used by companies active in the coalfields, 


\section{The new SANS 10320:2016 versus the 2014 Australian guidelines}

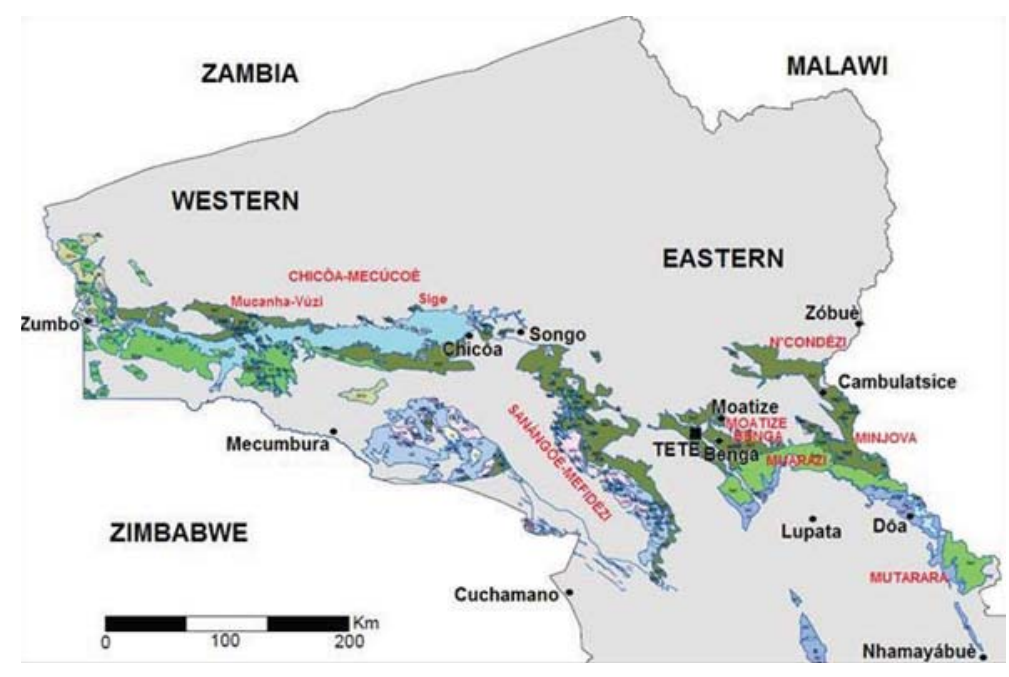

Figure 4-Map showing the sub-basins of the mid-Zambezi Valley (Vasconcelos, 2012)

and prior to October 2014 this meant that the more loosely constrained maximum distances between Points of Observation allowed for by the 2003 Australian Coal Guidelines could be used to define Coal Resources.

As an extreme example of how things stood prior to the new codes and coal guidelines, consider a South African CP utilizing the SAMREC Code (2009) and SANS 10320:2004 to define a coal resource in Mozambique. Based on a drill-hole spacing of $500 \mathrm{~m}$ and raw coal quality data, the CP would be able to disclose an Indicated GTIS Coal Resource, with no geological losses required. Even considering the changes proposed in the SANS 10320:2016 update that GTIS may not be reported, a 1.5 billion ton (Gt) opencastable GTIS Resource may drop by only 10-20\% (geological losses) if full seam extraction is considered, to give an MTIS Resource of 1.2$1.35 \mathrm{Gt}$. An Australian geologist considering the same resource and reporting in terms of the JORC (2012) code and 2003 Australian Guidelines (prior to October 2014) would be able to define a similar resource estimate in the Measured category and would not have to apply any geological loss.

Strict application of the Australian Guidelines (2014) may mean that many such publicly stated coal resources in Mozambique may have to be re-defined based on a geostatistical evaluation of the density and variability of their Points of Observation, as well as on all critical variables. Given that coal represents a heterogeneous mixture of constituents there is a large range of coal quality parameters that would have to be considered by the $\mathrm{CP}$, and geostatistical analysis on a ply-by-ply and variable-by-variable basis (as may be required in the Tete Province coalfields of Mozambique) would be extremely onerous and costly. Under the more stringent requirements of the Australian Guidelines (2014) it is also highly likely that several of the resource estimations made public prior to the new guidelines may have to be downgraded in tonnage and resource category, and that some isolated deposits in remote areas may not make it into the Resource category at all.

Since many of the coal deposits of Mozambique consist of thick interbedded seams, the application of the new SANS 10320:2016 guidelines would allow a spacing of $500 \mathrm{~m}$ for the Measured category (as for the 2003 Australian Coal
Guidelines), and we may in future therefore see previously JORC-compliant resources turning to the SAMREC Code (2016) and SANS 10320:2016 guidelines. The new SANS 10320:2016 guidelines, however, specifically mention that different coal deposit types within the same coalfield must be reported separately, and this would impact on the reporting of Mozambique coal resources, where both thick interbedded and multiple seam styles may occur within a coalfield or subbasin. Additionally, in structurally complex deposits, such as those found in Mozambique, it is structure (and not only coal quality) that can often be the critical resource-limiting determinant. Mozambique should therefore be considered to be a unique setting, with structural complexity far greater than seen in Australia or most of South Africa. As has been shown above, the rigid application of either the SAMREC (2016) or JORC Code (2014) may not be best practice, and Mozambique desperately requires a set of coal reporting guidelines of its own.

\section{Discussion}

There is no doubt that the revised Australian Coal Guidelines (2014) and SANS 10320:2016 guidelines are superior to their predecessors. The authors, however, contend that there is still one glaring omission in both the guidelines and controlling codes, and that is the failure to ensure a requirement for the lodging of the $\mathrm{CP}$ Report with the controlling exchange (such as is the case for the Toronto Stock Exchange).

While both the Australian Guidelines (2014) and the SANS 10320:2016 revision place more emphasis on the role of the $\mathrm{CP}$, neither address how to gauge (or maintain) the level of competency. Both the proposed SANS 10320:2016 update and the Australian Guidelines (2014) require that a Coal Resource geologist (whose core skills should be coal geology, modelling, and resource estimation) must also be familiar with Conversion (SANS 10320:2016) or Modifying Factors (Australian Guidelines, 2014). The Australian Guidelines (2014) further require the CP to be conversant with the potential product qualities, potential utilization, 


\section{The new SANS 10320:2016 versus the 2014 Australian guidelines}

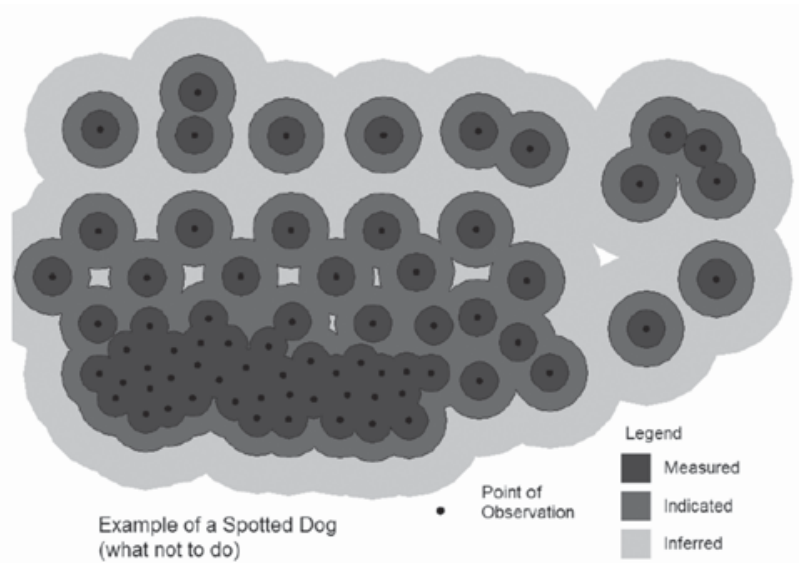

Figure 5-Example of a 'spotted dog' - what not to do (Australian Guidelines (2014), Figure 3

product yields and value, and mining horizon/target, which will undoubtedly require at least a mine plan and more realistically a pit shell for opencast mining. These aspects are more traditionally defined as the Modifying Factors, and fall within the realm of the mining engineer. It is therefore evident that the lines are becoming blurred in both codes, more notably so in the case of the Australian Guidelines (2014).

The SANS 10320:2016 update could also benefit from various considerations found in the new Australian Guidelines (2014), such as the geostatistical analysis of drillhole data. There are, however, some concerns with a geostatistical approach to resource classification in South Africa, the main one being that the creation of a robust semivariogram requires sufficient data-points, and that one cannot create a robust semivariogram if the data has a mix of different populations. Small coal Resource areas, such as are often found in South Africa, would require data-sets with drill-holes numbering far in excess of what is currently required for Resource reporting.

The authors also note that while the level of recovery through the seam is mandated in the revised SANS 10320:2016 guidelines, the level of that material reporting to the laboratory is not. We have come across many a South African example when it is stated that $95 \%$ recovery was obtained through the coal seam, yet less than $50 \%$ of the mass has been delivered to the laboratory.

One last point of discussion that arises from the new Australian Guidelines (2014) is the death of the spotted dog' (Figure 5) - the poor practice of estimating Measured, Indicated, and Inferred Resources over disconnected circles of influence around individual Points of Observation or along a line of Points of Observation (Stephenson et al., 2006).

The exclusion of such practice means that the new Australian Guidelines (2014) directly contradict the USA (USGS Circular 891) and Canadian (GSC Paper 88-21) systems, which are rules-based and prescriptive and which rely on the use of spotted-dog methodologies.

\section{Conclusions}

This paper has shown that while the parent codes (JORC and SAMREC) are very similar, the coal reporting guidelines for the two are not. In the case of the revised Australian Guidelines (2014) there is a significant increase in certain requirements, which include the application of geostatistical parameters to resource classification criteria, as well as expert knowledge of coal beneficiation, utilization, and mining practices. While this places an increased burden on the Competent Person (and, the authors believe, moves into the territory of reserving), the new codes and guidelines do at least mean that seeing a $1.5 \mathrm{Gt}$ Coal Resource reported with Reserves of only $200 \mathrm{Mt}$ will be a thing of the past.

\section{References}

AlLEN, J.P. and Fielding, C.R. 2007. Sequence architecture within a lowaccommodation setting: an example from the Permian of the Galilee and Bowen basins, Queensland, Australia. American Association of Petroleum Geologists Bulletin, vol. 91, no. 11. pp. 1503-1539.

Australian Guidelines for Estimating and Reporting of Inventory CoAl, Coal Resources and Coal Reserves. 2003 Edition. Coalfields Geology Council of New South Wales and the Queensland Mining Council, 2003. 8 pp.

Australian Guidelines for the Estimation and Classification of Coal Resources. 2014 Edition. Coalfields Geology Council of New South Wales and the Queensland Resources Council. 16 pp.

Bertoli, O., Paul, A., Casley, Z., and Dunn, D. 2013. Geostatistical drillhole spacing analysis for coal resource classification in the Bowen Basin, Queensland. International Journal of Coal Geology, vol. 112. pp. 107-113.

Dingemans, D. 2015. The update of the SAMREC \& SAMVAL Codes and SANS 10320: Progress and Changes. Presentation at the Witbank Recreation Club, March 2015.

Hancox, P.J. and GöTZ, A.E. 2014. South Africa's coalfields - a 2014 perspective. International Journal of Coal Geology, vol. 132. pp. 170-254.

JORC. 2012. Australasian Joint Ore Reserves Committee. Australasian Code for Reporting of Exploration Results, Mineral Resources and Ore Reserves (The JORC Code, 2012 Edition). The Joint Ore Reserve Committee of the Australasian Institute of Mining and Metallurgy, Australian Institute of Geoscientists and Minerals Council of Australia (JORC), (Effective 20 December 2012, mandatory 1 December 2013). 44 pp. http://www.jorc.org/docs/JORC_code_2012.pdf

Preston, K.B. and SAnders R.H. 1993. Estimating the in-situ relative density of coal. Australian Coal Geology, vol. 9. pp. 22-26.

SAMREC. 2007. South African Mineral Resource Committee. The South African Code for the Reporting of Exploration Results, Mineral Resources and Mineral Reserves (The SAMREC Code). 2007 Edition as Amended July 2009.61 pp. http://www.samcode.co.za/downloads/SAMREC2009.pdf

SAMREC. 2016. South African Mineral Resource Committee. The South African Code for the Reporting of Exploration Results, Mineral Resources and Mineral Reserves (the SAMREC Code). 2016 Edition. http://www.samcode.co.za/codes/category/8-reportingcodes? download=120: samrec

SANS 10320:2004. South African guide to the systematic evaluation of coal resources and coal reserves. Standards South Africa, Pretoria. $140 \mathrm{pp}$.

SANS 10320:2016. Systematic evaluation of coal exploration results, inventory coal, coal resources and coal reserves. Standards South Africa, Pretoria. [in press].

Stephenson, P.R., Allman, A., Carville, D.P., Stoker, P.T., Mokos, P., Tyrrell, J., and Burrows, T. 2006. Mineral Resource classification - it's time to shoot the 'spotted dog'! Proceedings of the Sixth International Mining Geology Conference, Darwin, NT, 21-23 August 2006. Australasian Institute of Mining and Metallurgy, Carlton, Victoria, Australia. pp 91-95.

VAn Deventer, K. 2015. Update of the Resource and Reserve Reporting Codes and Guidelines for the Coal Industry with specific focus on the SAMREC and SANS 10320 update. Progress and changes and the practical application thereof. Presentation for the SAMCODE Committee, September 2015.

VASConcelos L. 2012. Overview of the Mozambique coal deposits. Proceedings of the 34th International Geological Congress, Brisbane, QLD, Australia, 5-10 August 2012. Australian Geosciences Council. 25 pp. 